\title{
Application and Market of 1,4-butanediol Production of Reppe Method in China
}

\author{
Ping Luo, Xiaoding Li \\ Haiso Technology Co., Ltd., Wuhan, China \\ Email address: \\ lp98311@hotmail.com (Ping Luo)

\section{To cite this article:} \\ Ping Luo, Xiaoding Li. Application and Market of 1,4-butanediol Production of Reppe Method in China. American Journal of Chemical \\ Engineering. Vol. 9, No. 2, 2021, pp. 34-38. doi: 10.11648/j.ajche.20210902.11
}

Received: December 21, 2020; Accepted: March 9, 2021; Published: March 17, 2021

\begin{abstract}
The industrial production methods of 1,4-butanediol (BDO) are: maleic anhydride method (Davy-McKee), butadiene-acetic acid method (Mitsubishi Chemical), propylene oxide method (Lyondell), Reppe method, etc. Among these methods, only the Reppe process has achieved rapid development in China, with capacity far exceeding that of other petrochemical feedstock methods, because China has abundant mineral resources (e.g., coal and calcium carbide) where cheap feedstock is available for the production of 1,4-butanediol. There are three key steps in the production of 1, 4-butynediol by the Reppe method (methanol oxidation, alkynylation of formaldehyde and acetylene, and hydrogenation of 1, 4-butynediol). In recent years, Chinese enterprises have continuously explored and optimized these technologies introduced from abroad, and made some progress in process, equipment, catalyst, environmental protection and other related application technologies, which has promoted the technological progress of the industry. The latest statistical analysis is made on the application and market status of Reppe process for 1,4-butanediol production in China, and some opinions are put forward for the development of enterprises and 1,4-butanediol industry in the future, hoping to provide meaningful reference for the development of industry.
\end{abstract}

Keywords: 1,4-Butanediol, Reppe Method, BDO, Technology and Application

\section{Introduction}

1,4-butanediol (BDO) is an important organic and fine chemical raw material, which is widely used in the fields of medicine, chemical industry, textile, paper making, automobile and daily chemical industry. Its downstream derivatives include tetrahydrofuran (THF), polybutylene terephthalate (PBT), $\gamma$-butyllactone (GBL) and polyurethane (PU), coatings and plasticizers. THF can be used to produce polytetramethylene glycol (PTMEG), which is a raw material for the synthesis of spandex, polyether elastomer and thermoplastic polyurethane. In addition, BDO can be used as solvents, coating resins and pharmaceutical intermediates [1]. In recent years, with the stimulation of BDO downstream product consumption, the average annual growth rate of BDO demand has reached $20 \%$ [2], and some enterprises have also embarked on BDO projects or expanded their production capacity on the existing basis. By the end of 2017, the annual capacity of BDO in the Chinese mainland is 2.079 million tons, accounting for about $52.1 \%$ of the global total capacity, making it the country with the largest capacity in the world [3].
Reppe method, in particular, is growing fastest, accounting for about $75 \%$ of the country's total capacity by 2019 . In this paper, the technical application and market status of 1,4-butanediol production by Reppe method are introduced.

\section{Technology and Application of Reppe Method to Produce 1,4-butanediol}

The production process of BDO by Reppe method is divided into three steps: methanol oxidation to produce formaldehyde, acetylene and formaldehyde to produce 1, 4-butynediol and 1, 4-butynediol hydrogenation to produce BDO. See Figure 1 for the process diagram.

This technology is mainly developed in Germany and the United States. At present, ISP process and INVIST process are mainly used in China. The most significant difference between them lies in the acetylenal reaction section. The former is continuous operation of several reaction stills, while the latter is continuous operation of one reaction still. The catalysts used in the two processes are also different. The former is a copper 
catalyst with carrier, while the latter is a copper catalyst without carrier. In recent years, the catalyst used in the first two steps has made breakthroughs in china enterprises. In addition, the third step, 1, 4-butynediol hydrogenation process has its own improvement in China, and the catalyst used is different from that used abroad.

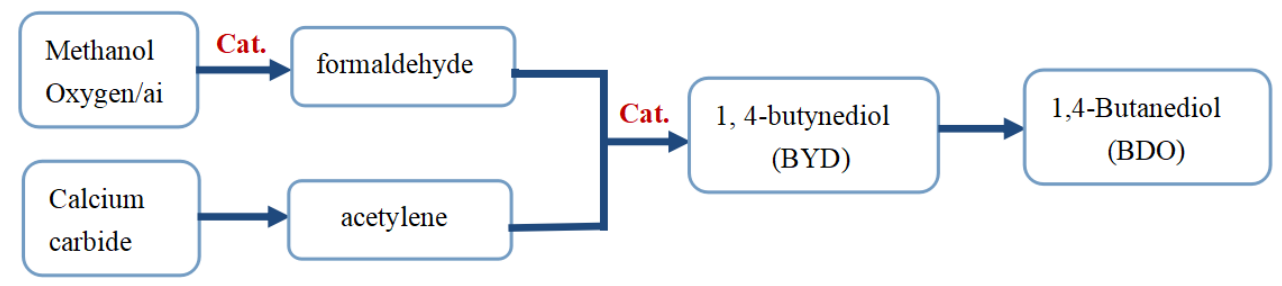

Figure 1. Production of 1,4-butanediol process diagram Reppe method.

\subsection{Methanol Oxidation to Formaldehyde}

The first step of the Reppe process is the oxidation of methanol to produce formaldehyde. Depending on the catalyst used and the production process, there are two different process routes: the silver method also known as the "methanol excess method" and the iron molybdenum method also known as the "air excess method" [4].

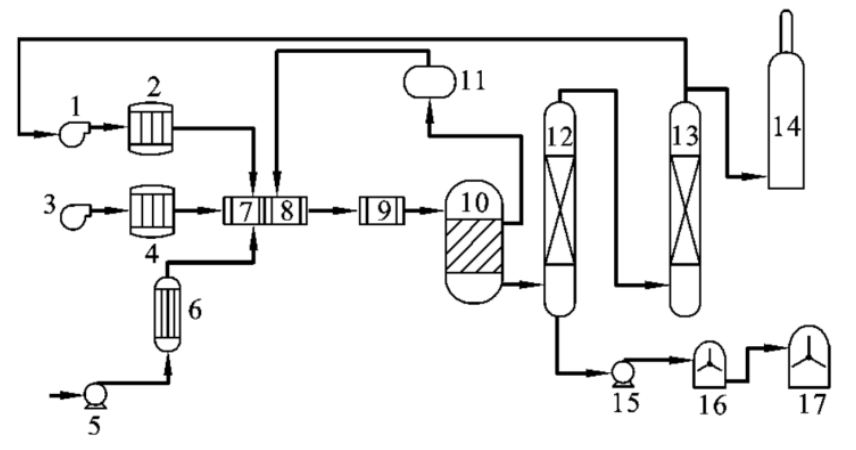

Figure 2. Silver Formaldehyde Process.

1. Exhaust fan; 2. Exhaust heater; 3. Air fan; 4. Air preheater; 5. Methanol pump; 6. Reboiler; 7. Mixer; 8. superheater; 9. Fire retardant filter; 10. Reactor; 11. Drum; 12/13. Absorption tower; 14. Incinerator; 15. Circulating pump; 16. Configuration slot; 17. Finished product tank

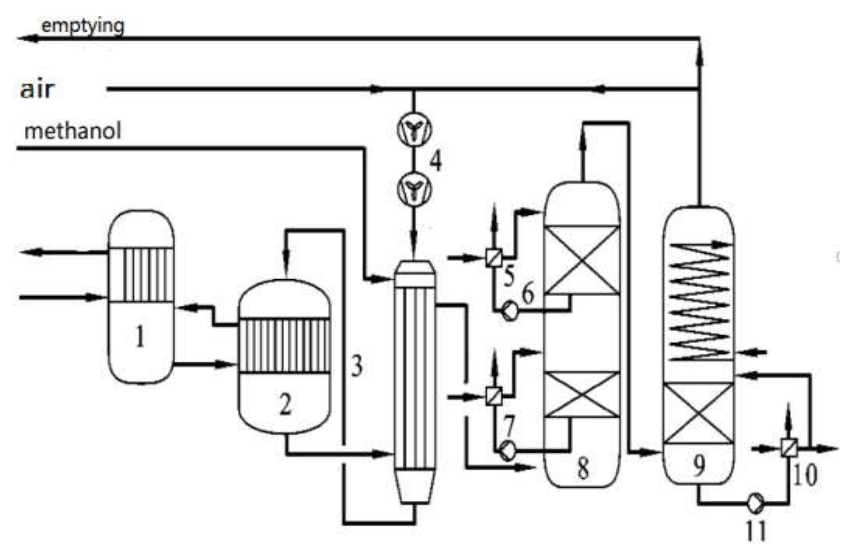

Figure 3. Fe-Mo Formaldehyde Process.

1. Waste heat boiler; 2. Reactor; 3. Methyl alcohol evaporator; 4. Circulation fan; 5/10-Cooler 6. Circulating pump; 7. Cooler circulating pump; 8. 9 Absorption tower; 11. The product pump

At present silver method formaldehyde production is widely used in small and medium-sized formaldehyde production enterprises in China. Although its process is simple and mature, equipment investment is small, regulation elasticity is large, tail gas containing hydrogen can be recovered and burned, catalyst cost is low, power consumption is low, catalyst replacement is convenient, but its catalyst stability is relatively low and the life is short, replacement is frequent, conversion rate is low can only produce low concentration of formaldehyde. After 1980, the iron-molybdenum method has exceeded the silver method. The methanol conversion rate of iron - molybdenum method is higher and energy consumption per unit is lower than that of silver method, the catalyst life and production capacity are relatively large. The iron-molybdenum method can produce high concentration of formaldehyde, But its one-time investment is biger. At present, China's BDO project, polyformaldehyde project and other high concentration formaldehyde production mostly adopts iron-molybdenum process [5]. However, the iron-molybdenum process is basically an imported process at present, mainly the American D. B. Wester process and The Swedish Perstorp process. The technology transfer cost is relatively high, and the catalyst is imported, which leads to a long procurement cycle and high equipment investment and catalyst cost. The first set of PerstorP formaldehyde device introduced into China from Sweden was successfully started in 1996. After many years of practice, these devices generally operate smoothly, but there are still some differences between the enterprises using them. In terms of catalysts, domestic catalysts with performance up to foreign level have been developed. For example, iron-molybdenum catalysts independently developed and produced by HAISO Technology in 2016 have been applied in xinjiang enterprises [6].

\subsection{Acetyl Aldehyde Reaction}

The catalytic and synthesis of 1, 4-butynediol by acetylene and formaldehyde was developed in Germany in the 1930s and has undergone 80 years of development and industrial application. Meanwhile, the process from the initial fixed bed to suspension bed, slurry bed. The catalyst was developed from large particle silicon carrier to fine powder magnesium silicate carrier, to no carrier. This development process can be divided into classical Reppe method and modified Reppe method. Although the classic Reppe method requires no 
separation of catalyst and product and has low operating cost, the reactor design safety factor is as high as 12-20 times due to the high partial pressure of acetylene, which is prone to explosion. So the reaction device is huge, the equipment cost is high, and the investment cost is high. Secondly, in this process, acetylene on the catalyst can be polymerized to form polyacetylene, which not only leads to the inactivation of the catalyst quickly, but also clogs the pipeline, thus shortening the production cycle and reducing the production capacity.

At present, the classic Reppe method is basically eliminated, and the improved Reppe process is as follows: acetylene and formaldehyde are reacted in a series reaction system of 3 4 slurry bed reactors, and the catalyst is modified $\mathrm{Cu}$ catalyst, with mild reaction conditions, safety factor and high product yield. All the 1, 4-butynediol devices introduced in China are developed after improved Reppe method or digestion and absorption to suit the characteristics of domestic enterprises. Its processes are represented by the floating bed of BASF, DuPont, and ISP (formerly GAF) as shown in Figure 4. In recent years (after 2011) many of the BDO projects that have been launched or expanded have begun to introduce the relatively simple INVISTA process.

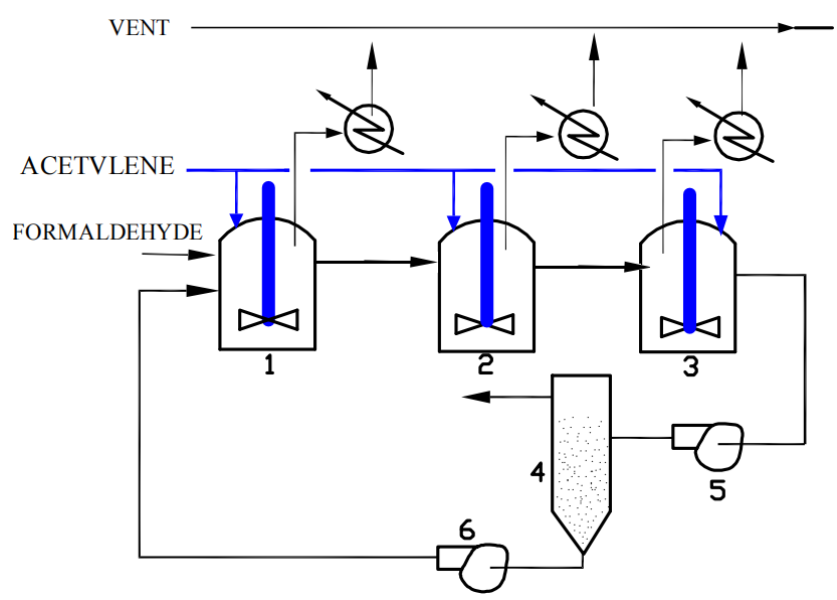

1, 2, 3-Reactor; 4-Concentrator; 5-Circulating pump

Figure 4. ISP process alkynal system 1,4-butynediol process.

These imported devices are running well in domestic enterprises at present, and the indicators in production are also within the control range, but some enterprises have differences in the use process. The high cost of catalyst import and the treatment of deactivated catalyst are also problems faced by enterprises. Although there are now professional enterprises can be acquired, but the enterprise in a period of time to store a large number of deactivated has become hazardous waste catalyst. This process also has a large number of "three wastes" also need to pay the cost of enterprises to solve. For this reason, HAISO Technology independently developed an alkynating catalyst for ISP process and successfully tried it in Xinjiang industry in 2016 [7]. Dalian Reak Science \& Technology has developed an alkynating catalyst for INVISTA process [8], and has reported industrial application. Xinjiang Markor Chemical Co., LTD has also done research on catalyst regeneration [9]. Some domestic enterprises have also invented some environmental protection treatment processes in the treatment of three wastes [10].

\subsection{1, 4-butynediol (BYD) Hydrogenation}

Reppe method of 1, 4-butynediol hydrogenation production BDO technology and catalyst were developed by BASF, DuPont, Linde, GAF, SK and other foreign companies. The process can be divided into two types: the first is one-step hydrogenation. The reaction is carried out under $30 \sim 32 \mathrm{MPa}$ over a nickel-based catalyst (generally Rani nickel) supported by alumina or silica gel in a fixed bed. The second step is Multi-step (two-step or three-step) hydrogenation. The first step is to adopt a slurry bed (or suspension bed) reactor and use Rainie nickel or $\mathrm{Pd} / \mathrm{Al}_{2} \mathrm{O}_{3}$ catalyst for partial hydrogenation under $2 \sim 3 \mathrm{MPa}$ to obtain liquid product which are made of $65 \%$ water, $30 \%$ BDO and a small amount of unsaturated carbonyl compounds [11]. In the second step, a fixed bed or trickle bed was used, with $\mathrm{Ni} / \mathrm{SiO}_{2}$ or $\mathrm{Ni}-\mathrm{Cu}-\mathrm{Mn} / \mathrm{SiO}_{2}$ (or $\mathrm{Al}_{2} \mathrm{O}_{3}$ carrier) as catalyst, and the reaction pressure was $10 \sim 20 \mathrm{MPa}$. The total conversion rate of multi-stage hydrogenation of butanediol was $100 \%$, and the selectivity of butanediol was $95 \%$.

At present, the domestic process and catalysts are mainly introduced from abroad. In 2000, Shanxi Sanwei Group Co., Ltd introduced a 10,000-ton Reppe method of two-stage hydrogenation plant to produce 1,4-butanediol using coal as raw material from abroad. After that, it cooperated with Shanxi University to develop a second-stage hydrogenation catalyst, and then carried out an innovative design of the process. In addition, Novel Environmental Protection New Materials (Shanghai) Co., Ltd. also studied and developed the low-pressure home-made hydrogenation catalyst [12].

\section{Application and Market Status of Reppe Production BDO Technology}

BDO has a variety of production technologies. At present, there are five main industrialized methods in the world: Reppe method, butadiene acetylated method, propylene alcohol method, maleic anhydride esterification and direct maleic anhydride hydrogenation [13]. The main processes in these processes are Reppe method and maleic anhydride hydrogenation. But raw material of maleic anhydride is affected greatly by crude oil price. At present, the global production of 1,4-butanediol by Reppe method accounts for more than $40 \%$ of the total production, and maleic anhydride method accounts for more than $30 \%$. However, according to the current status of China's raw materials (cheap calcium carbide) and mature coal-to-methanol production technology, most of the domestic production processes adopt the foreign improved Reppe method [14]. In recent years, especially after 2011, many domestic enterprises started to build and expand $\mathrm{BDO}$ projects after seeing the rich profits of BDO, forming the second period of rapid expansion. In this development process, Reppe method, maleic anhydride method and propylene alcohol method, which are the three main process methods for 
BDO production, basically maintained a growth ratio of about $70 \%$. In $2019,75 \%$ of the domestic production capacity was Reppe method. In terms of local production capacity process structure, in the northwest of China, the production capacity has grown most rapidly in recent years. Relying on relatively cheap calcium carbide, Reppe process has grown rapidly. The second is the east of China, mainly by maleic anhydride method and propylene alcohol method. The following table shows the production capacity and application process of major BDO enterprises in China from 2015 to 2019.

Table 1. 2015-2019 annual production capacity of China's major BDO enterprises and technology.

\begin{tabular}{|c|c|c|c|}
\hline No. & Company & Capacity (Ten thousand tons) & Production methods \\
\hline 1 & Shanxi Sanwei Group Co., Ltd & 15 & 7.5 Reppe (ISP)+7.5 (Maleic anhydride) \\
\hline 2 & Shaanxi Bidou Chemical Co., LTD & 13 & 3.0 Reppe (ISP)+10 (INVIST) \\
\hline 3 & Henan Kaixiang Fine Chemical Co., LTD & 10 & Reppe (ISP) \\
\hline 4 & Inner Mongolia Dongyuan Technology Co., LTD & 20 & Reppe (INVIST) \\
\hline 5 & Shaanxi Shenmu Guorong Fine Chemical Co., LTD & 6 & Reppe \\
\hline 6 & Han Cheng Black cat Chemical Co., LTD & 6 & Reppe \\
\hline 7 & XinJiang Markor Chemical Co., LTD & 26 & 6 Reppe (ISP)+20 (INVIST) \\
\hline 8 & Sichuan Tianhua Co., LTD & 9 & Reppe (INVIST) \\
\hline 9 & Yanchang Petroleum Mining Co., LTD & 10 & Reppe \\
\hline 10 & Sinopec Great Wall Energy Chemical Ningxia Co., LTD & 20 & Reppe (INVIST) \\
\hline 11 & $\begin{array}{l}\text { Hebi Coal Chemical Industry Co., Ltd. of Henan Energy and } \\
\text { Chemical Industry Group }\end{array}$ & 10 & Reppe (ISP) \\
\hline 12 & Xinjiang Xinye Energy chemical Co., LTD & 5 & Reppe (INVISA) \\
\hline 13 & Sichuan Vinylon Factory of Sinopec Group & 20 & Reppe \\
\hline 15 & Xinjiang Tianye (Group) Co., LTD & 20 & Reppe (ISP) \\
\hline 16 & Xinjiang Blue Ridge Tunhe Chemical Co., LTD & 23.8 & Reppe \\
\hline 17 & Xinjiang Guotai Xinhua Mining Co., LTD & 20 & Reppe \\
\hline 18 & Yunnan Yunwei Group Co., LTD & 2.5 & Reppe (ISP) \\
\hline 19 & Chang Chun Dairen (PanJin) Chemical Co., LTD. & 15 & Propylene glycol \\
\hline 20 & Sinopec Yizheng Chemical Fibre CO., LTD. & 10 & Maleic anhydride \\
\hline 21 & NingBo JiangNing Chemical Co., LTD. & 7 & Maleic anhydride \\
\hline 22 & Zhejiang Huachen Energy Co., LTD & 5.5 & Maleic anhydride \\
\hline 23 & China Bluestar (Group) Co., LTD & 10 & Maleic anhydride \\
\hline 24 & Shandong Huiying New Material Technology Co. LTD & 5.5 & Maleic anhydride \\
\hline
\end{tabular}

As can be seen from Table 1, the capacity of BDO in China will reach 3 million tons by 2019. Although the output of resin and spandex in the downstream industry of BDO has increased under the stimulus of BDO's capacity expansion, the overall apparent consumption of BDO is estimated to be around 1.5 million tons. Obviously, even at an average operating rate of $60 \%$, domestic BDO overcapacity is obvious. It is reported that in the future, the capacity under construction or planned to be nearly one million tons, and the scale of equipment tends to be large, while the downstream product demand growth rate cannot keep pace with the BDO capacity growth rate, so the industry competition will become increasingly fierce. BASF plans to shut down its $25 \mathrm{kT}$ /a BDO plant in Chiba Japan in December 2020 due to the reduction of market demand for 1, 4-butanol (BDO) in Japan and the production of a new coal-based BDO plant, which leads to overcapacity in Asia [15].

At the same time, in order to avoid or reduce the pressure of excess capacity of BDO, more and more enterprises have turned to the downstream derivative products of BDO, such as PTMEG, PBT and GBL. Although the demand growth of BDO's downstream derivatives is fast in recent years, it still lags behind the capacity growth of BDO. Therefore, BDO enterprises may transfer the pressure of BDO overcapacity to the downstream industry chain, thus affecting the whole industry chain.

\section{Conclusion}

In recent years, especially after 2011, some domestic enterprises have started to build and expand BDO projects after seeing the rich profits brought by BDO. In these projects, Reppe law occupies an absolute advantage with its relatively low cost. Today, China's BDO capacity has exceeded 3 million tons, overcapacity is obvious. In this situation, some enterprises have established the BDO industrial chain in order to flexibly adjust and control the product structure, conform to the market, reduce the pressure on the production capacity of upstream products, and enhance the competitiveness of downstream products. However, the demand growth of downstream products is limited, so enterprises should prevent BDO excess capacity from being transferred to the downstream, which will lead to greater investment pressure. The reform and transformation of the main domestic BDO enterprises is imminent. The main direction of BDO enterprises in the future will be to control the excessive expansion of production capacity, stabilize domestic demand and consumption, and increase the investment in sophisticated technologies.

"In the era of excess, reducing costs" should be attached great importance to BDO enterprises. Relevant enterprises can consider measures such as replacing imported catalysts with 
domestic catalysts, improving the process, and strengthening production management to reduce production costs. For power enterprises with large production capacity, they can do a good job in the BDO industry chain, accelerate the breakthrough of the core technology of new derivative products in the downstream, and do a good job in product quality and service to reduce overcapacity.

\section{References}

[1] Anfu, Zhou Shuli, Hui Quan. Development and Market Prospect of 1,4-butanediol [J]. Contemporary Petrochemical Industry, 2010, 5: 19.

[2] National Coal Chemical Industry Information Station. Analysis of 1,4-butanediol Industry in China [J]. Coal Chemical Industry, 2011, 2: 4.

[3] Shang Rujing, Mu Shifang, Niu Gang, et al. Market analysis of coal based 1,4-butanediol and its derivative fine chemicals [J]. Modern Chemical Industry, 2018, 38 (2): 11.

[4] Xu Yongcheng, Xiao Dunfeng, Liu Guangzhi. Discussion on the technology of methanol oxidation to formaldehyde [J]. Chemical fertilizer design, 2012, 50 (3): 24 25.

[5] Sun Jiguang. Analysis and Comparison of the Process technology of producing formaldehyde by electrolytic silver method and iron molybdenum method [J]. Chemical technology and development, 2012, 41 (5): 29.

[6] Zhang Xiongbin, Lin Tao-hai, Deng Jiankang, et al. Industrial Application of EQ-101 iron-Molybdenum-Formaldehyde Synthesis Catalyst [J]. Coal chemical industry, 2019, 47 (1): 32.
[7] Luo Ping, Deng Jiankang, Jiang Jijun, et al. Industrial application of synthesis of 1, 4-butynediol EQ-201 alkynating catalyst [J]. Coal chemical industry, 2019, 47 (6): 9.

[8] Zhou Huanwen, Deng Shaoliang. A catalyst for the production of 1, 4-butynediol and its preparation method: China, CN103480382A [P].2014-01-01.

[9] Tang Jiwei, Sun Jiguang, Li Xingyi. A gas burner for regenerating oxidation furnace with 1, 4-butynediol catalyst: China, CN202868677U [P]. 2013-04-10.

[10] Xiao Ming. Research progress on synthesis of 1,4-butanediol by Reppe method [J]. Fine and Specialty Chemicals, 2019, 27 (4): 44.

[11] Xu Yalin. Preparation of $\mathrm{Ni} / \mathrm{Al}_{2} \mathrm{O}_{3}$ Catalyst with high hydrothermal stability and Study on Hydrogenation of Butynediol [D]. Shanxi: Shanxi University, 2010.

[12] Fang Zhiyong, LI Gaolin. Localization of low pressure Hydrogenation catalyst for 1,4-butanediol and its Industrial application [J]. Industrial catalysis, 2020, 28 (5): 69.

[13] Wang Wei, Liang Qianqian, Tang Jialin. Production technology and market profile of 1,4-butanediol [J]. Chemical intermediates, 2006, 7: 20.

[14] Cao Hongzhong. Route Selection and Analysis of 1,4-butanediol Process [J]. Coal and Chemical Industry, 2019, 42 (10): 123-128.

[15] Sinopec Organic raw material Science and Technology Information Center station, BASF intends to shut down Japan 1,4-butanediol plant [J]. Petrochemical Technology and Economy, 2020, 5: 53. 